Article

\title{
Impact of Microwave Plasma Torch on the Yeast Candida glabrata
}

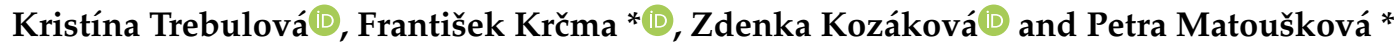 \\ Faculty of Chemistry, Brno University of Technology, Purkyňova 118, 61200 Brno, Czech Republic; \\ xctrebulovak@vutbr.cz (K.T.); kozakova@fch.vut.cz (Z.K.) \\ * Correspondence: krcma@fch.vut.cz (F.K.); matouskova@fch.vut.cz (P.M.)
}

Received: 30 June 2020; Accepted: 6 August 2020; Published: 11 August 2020

check for updates

Featured Application: A cold gaseous plasma torch generated in argon at low powers and atmospheric pressure is applicable in medicinal treatment where it could significantly decrease microbial skin or tissue contamination in a short time and with low operating costs.

\begin{abstract}
Recently, various cold plasma sources have been tested for their bactericidal and fungicidal effects with respect to their application in medicine and agriculture. The purpose of this work is to study the effects of a $2.45 \mathrm{GHz}$ microwave generated plasma torch on a model yeast example Candida glabrata. The microwave plasma was generated by a surfatron resonator, and pure argon at a constant flow rate of $5 \mathrm{Slm}$ was used as a working gas. Thanks to a high number of active particles generated in low-temperature plasma, this type of plasma has become highly popular, especially thanks to its bactericidal effects. However, its antimycotic effects and mechanisms of fungal inactivation are still not fully understood. Therefore, this study focuses on the antifungal effects of the microwave discharge on Candida glabrata. The main focus is on the measurement and evaluation of changes in inactivation effects caused by varying initial concentration of Candida glabrata cells, applied microwave power and exposure time. The discharge was applied on freshly inoculated colonies of Candida glabrata spread on the agar plates and its inhibitory effects were observed in the form of inhibition zones formed after the subsequent cultivation.
\end{abstract}

Keywords: microwave discharge; surface wave sustained discharge; atmospheric pressure plasma torch; low-temperature plasma; plasma sterilization; yeast inactivation; Candida glabrata

\section{Introduction}

In recent decades, a number of recently discovered pathogenic microorganisms has rapidly grown, and their resistance to antibiotics or antifungals has increased as a result of the excessive use of antibiotics, antifungals and immunosuppressants (drugs that suppress the function of the immune system) [1,2]. Therefore, the attention of scientists has focused on finding new ways to inactivate unwanted microorganisms (ideally without the side effects or potential enhancement of microorganism resistance). This problem has led to the introduction of a new interdisciplinary field called plasma medicine that combines physics, biology and chemistry in exploring new possibilities for food sterilization, sterilization of medical equipment and tools or direct therapeutic treatments of various diseases.

Plasma technologies and their applications in the food and biomedical industries have become one of the latest trends in the scientific research of our century. Plasma used for food or living tissue exposure must operate with a neutral gas temperature of around $20-50{ }^{\circ} \mathrm{C}$ to prevent a degradation of vitamins, proteins and other biological and biologically active substances, or to prevent an injury or the discomfort of living organisms in the case of biomedical applications [3-9]. On the other hand, 
the used gas must be sufficiently activated, which means that it must contain a high concentration of reactive particles (ions, radicals, excited species) initiating microbial inactivation. These conditions can be very efficiently fulfilled by the atmospheric pressure nonthermal plasma (APNTP, also called Cold atmospheric plasma-CAP), where the neutral gas temperature (temperature related to the kinetic motion of heavy particles-atoms, molecules and ions) remains close to the environment, but the temperature of free electrons usually reaches thousands of Kelvin. Using conventional gases such as air or argon, it is possible to produce Reactive oxygen species (ROS) and Reactive nitrogen species (RNS) [10,11], ozone [1], oxides and peroxides [2] in a very short time. In addition, nonthermal plasmas efficiently produce ultraviolet (UV) radiation in the UVC region and vacuum ultraviolet (VUV) radiation, which both have strong antimicrobial effects [12-14]. Devices [15] effectively producing such type of plasma are based on the corona discharge [16], dielectric barrier discharge (DBD) [17], atmospheric pressure glow discharge [18], plasma beam or nanosecond pulsed discharge [19].

In the food industry, plasma is mainly used to sterilize equipment and instruments, and studies are being carried out on the possible application of plasma for the sterilization of fruit and fruit juices, mainly due to the proven integrity of vitamins and active substances [20]. In biomedical applications, plasma is also used for the sterilization of equipment and tools, and several pilot studies focus on the treatment of skin diseases, cancer or superficial injuries [3,21]. Different systems were used for the study of selected yeast properties after plasma exposure. The yeast proteomics were studied using both discharges in the gaseous phase and in gaseous bubbles in the liquid phase [22]. The corona discharge was used for the apoptosis study of Saccharomyces cerevisiae in [23]. The role of oxidative stress in the yeast apoptosis after the exposure to the transient spark discharge was evaluated in [24]. Studies of various discharges for the antifermentation treatment of juices, mainly apple juice, are relatively popular. The corona discharge was used by $[20,25]$, and the transient spark was used for this purpose in [26]. The gliding arc discharge was used for the cold sterilization of tomato juice in [27]. A few studies were also completed using the surface discharge for the determination of the selected active species role in the direct tissue treatment $[28,29]$.

Our recently developed surface wave-initiated microwave torch [30-35] can also be a source of low-temperature plasma. In this case, the plasma is produced by an electromagnetic wave that travels along the interface between the plasma and the dielectric [36]. Standardly, we used argon as a carrier gas for the plasma generation and the yeast treatment because it is much cheaper than helium and colder than common atmospheric pressure discharges in air such as DBDs, corona or glow discharges [34].

In the microwave discharge, the plasma has a higher electron temperature than plasma obtained by the indirect and high-frequency discharge. Due to the high temperature of the electrons, there is also a higher dissociation and ionization degree, which is reflected in a wide range of uses of this type of discharge including wound healing [30-33], surface decontamination of fruits [34] or deposition of thin layers [35]. This paper focuses on the first use of this discharge in the yeast Candia glabrata as a model microorganism.

Candida glabrata is classified as a nondimorphic yeast that exists as a small blastocoid. In fact, Candida glabrata is the only species of the genus Candida that does not form pseudohyphae at temperatures above $37^{\circ} \mathrm{C}$. A distinguishing feature between Candida glabrata and better known and investigated Candida albicans is its haploid genome (in contrast to the diploid genome of Candida albicans). Interestingly, Candida glabrata is more genetically related to baker's yeast (Saccharomyces cerevisiae) than to Candida albicans or Candida parapsilosis [37,38].

Candida glabrata can be found in the human body as a part of its natural microflora, mainly in the gastrointestinal tract, mouth or genital area. Candida glabrata is usually well controlled or harmless in healthy people. However, it may cause problems to people with a suppressed immune system. Particularly at risk are hospitalized patients, people with HIV, people being treated for cancer and people who have had organ transplants [39].

The danger of the infections caused by Candida glabrata lies in its innate resistance to the azole antifungal therapy, which is very effective in treating infections caused by other Candida species. 
Candida glabrata retains many other virulence factors, such as the ability to adapt quickly to stressful conditions and the ability to secrete phospholipases, lipases and hemolysins, which contribute to an extreme aggression leading to a low therapeutic response and severe recurrent candidiasis. Among the most crucial virulence factors is the expression of the gene adhesin, thanks to which the organism can adhere to biotic and abiotic surfaces in microbial substrates. Adhesin expression is the mechanism by which Candida glabrata produces fungal biofilms that have been shown to be more resistant to antifungals than planktonic cells. The ability to form biofilms is considered to be the most important virulence factor of Candida glabrata. Biofilms are known as the surface-associated communities of microorganisms embedded in the extracellular matrix that require significant antifungal therapy and host immune responses [40,41].

Infections caused by the yeasts of the genus Candida are called candidiasis. Candinda glabrata is currently ranked the second or third in the world as a cause of superficial (oral, esophageal, vaginal, urinary) or systemic candidiasis [40]. Based on these facts, there is an emergent necessity to find new nontraditional ways to inactivate this yeast.

\section{Materials and Methods}

\subsection{Microwave Plasma Jet Set Up}

A low power solid state microwave power supply operating at frequency of $2.45 \mathrm{GHz}$ (Sairem, GMS $200 \mathrm{~W}$ ) was connected by a flexible coaxial cable to a commercial compact electromagnetic surface wave (SW) launcher (Sairem, SURFATRON 80). The discharge was created in a quartz capillary (real dielectric permittivity $\varepsilon_{r}=3.2541$, imaginary dielectric permittivity $\varepsilon_{i}=0.0062$, i.d. $3 \mathrm{~mm}$, o.d. $8.0 \mathrm{~mm}$ ) in argon (purity of $99.9965 \%$ ) at a constant mass flow rate of $5 \mathrm{Slm}$, controlled by the Bronkhorst FG201-CV mass flow controller. The experimental set up is shown in Figure 1. The experiments were performed at 2 different powers $(9 \mathrm{~W}, 12 \mathrm{~W}$; maximal reflected power was below $0.5 \mathrm{~W}$ ), thanks to which the surface temperature of the agar plates stayed within the temperature tolerance of the living tissues [3]. Based on our previous results obtained by the thermal camera, the temperature of the treated object did not exceed $40^{\circ} \mathrm{C}$ even after $30 \mathrm{~s}$ of the treatment [34], but higher temperatures at treatment times above $30 \mathrm{~s}$ were possible. The applied powers of $9 \mathrm{~W}$ and $12 \mathrm{~W}$ were selected based on our experience presented in the same study. The rotational temperature (indicating the real temperature of the plasma core) was obtained from the emission spectrum of the $\mathrm{OH}$ radical and it reached $650 \pm 50 \mathrm{~K}$ at the end of the quartz capillary and decreased linearly to $600 \pm 50 \mathrm{~K}$ on the treated surface [34]. The visible end of the discharge was directed perpendicularly to the treated area approximately at the center of the agar in the sterile petri dishes so that the visible end of the beam did not touch the surface. In the case of $9 \mathrm{~W}$, the distance from the top of the inoculated culture was $5 \mathrm{~mm}$ while using $12 \mathrm{~W}$; the discharge torch was longer so the distance between its visible end and the treated area was reduced to $3.5 \mathrm{~mm}$. The distribution of active particles and calculated plasma parameters at similar operating conditions were described in detail in [34].

\subsection{Preparation of Candida Glabrata Samples}

For the preliminary testing of the antimicrobial activity of the microwave plasma, the yeast strain Candida glabrata CCM 8270 was used. This testing strain was supplied by the Czech Collection of Microorganisms in Brno [42]. The yeast culture was grown in the GPY liquid medium (Glucose Yeast Peptone, HiMedia, India) for $24 \mathrm{~h}$. The temperature of cultivation was $37^{\circ} \mathrm{C}$.

Then, the yeast culture $\left(50 \mu \mathrm{L} ; 1 \times 10^{7} \mathrm{CFU} / \mathrm{mL}\right)$ grown for $24 \mathrm{~h}$ was cultivated on the surface of the agar medium in the Petri dishes. Agar plates were prepared using the commercial medium Malt Extract Agar Base (HiMedia, India) and Petri dishes with a diameter of $52.6 \mathrm{~mm}$ were used. For the antimicrobial activity testing of the microwave generated torch, three different concentrations of microorganisms were used $\left(24 \mathrm{~h}\right.$ culture with concentration $1 \times 10^{7} \mathrm{CFU} / \mathrm{mL}$ and a 10 -fold and 100 -fold diluted culture). The cell concentration was calculated from the absorbance value measured 
spectrophotometrically at $\lambda=630 \mathrm{~nm}$ and from the experimentally determined calibration curve dependence of absorbance on the concentration of the Candida glabrata cells $(\mathrm{CFU} / \mathrm{mL})$.

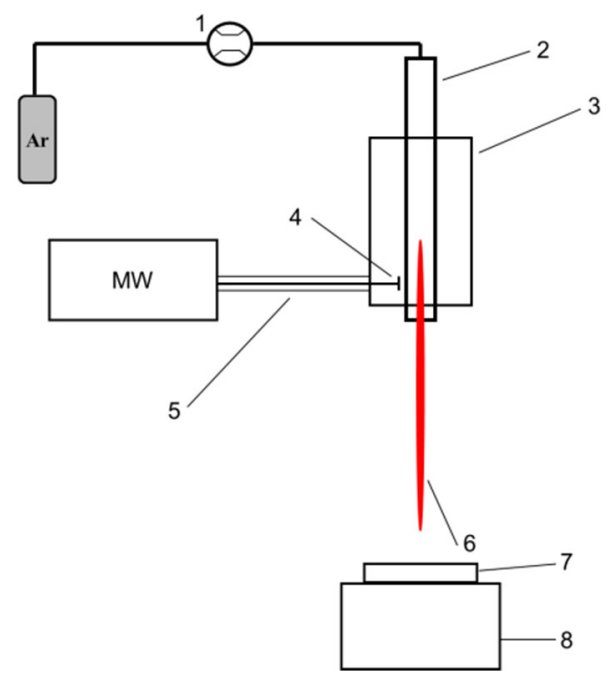

Figure 1. Scheme of the experimental set up: 1-mass flow controller; 2-quartz capillary; 3-surfatron resonator; 4-MW antenna; 5-MW-coaxial cable; 6-plasma beam; 7-Petri dish with inoculated Candida glabrata culture; 8-Petri dish holder.

The plasma torch was applied on the prepared agar plates with microbial samples at selected conditions (see Results). After the plasma application, the agar plates were incubated at $37^{\circ} \mathrm{C}$ for 24 and $48 \mathrm{~h}$. The microbial inhibition of the plasma was determined by measuring the clear inhibition zone of microorganism growth and recorded as an area of the inhibition zone in square centimeters. Their sizes were measured using Microsoft Power Point where an ellipse or a circle was drawn over each zone and a corresponding dish. Their diameters and heights were recalculated to fit the real dimensions of the Petri dishes with a diameter of $52.6 \mathrm{~mm}$. Each sample was treated by the plasma twice independently, and the inhibition zone measurement was realized independently three times for each sample to eliminate random errors.

\subsection{Application of the Discharge}

Petri dishes with the freshly inoculated Candida glabrata cultures were treated under the microwave plasma torch for selected exposure times of 10,30, 60 and $120 \mathrm{~s}$ at a microwave power of 9 and $12 \mathrm{~W}$, and $300 \mathrm{~s}$ at $9 \mathrm{~W}$, only. Each Petri dish was treated individually. All the measurements were performed twice, and the control sample (without the plasma treatment) was preserved for each yeast concentration. After the plasma application, the Petri dishes were incubated at $37^{\circ} \mathrm{C}$ for $48 \mathrm{~h}$. Documentation in a form of photographs of all Petri dishes was recorded after 24 and $48 \mathrm{~h}$.

\subsection{Statistical Analysis}

All results are presented as the mean \pm standard deviation (SD). The data analysis was performed using Microsoft Excel with the Data Analysis Toolpack. Statistical significance was determined via the one-way analysis of variance ANOVA at a significance level of $5 \%(p \leq 0.05)$.

\section{Results and Discussion}

Three factors and their impact on the inhibition zone size and its time stability were measured:

(a) Plasma exposure time;

(b) Applied microwave power;

(c) Initial cell concentration. 


\subsection{Plasma Exposure Time Impact}

Comparing the sizes of the inhibition zones, it was found that the size of the inhibition zones increased more or less linearly with the plasma treatment duration. Thus, the longer the exposure time is, the bigger the inhibition zone achieved (see Figure 2). This correlation was observed at all test concentrations and applied powers (see Figures 3-5).
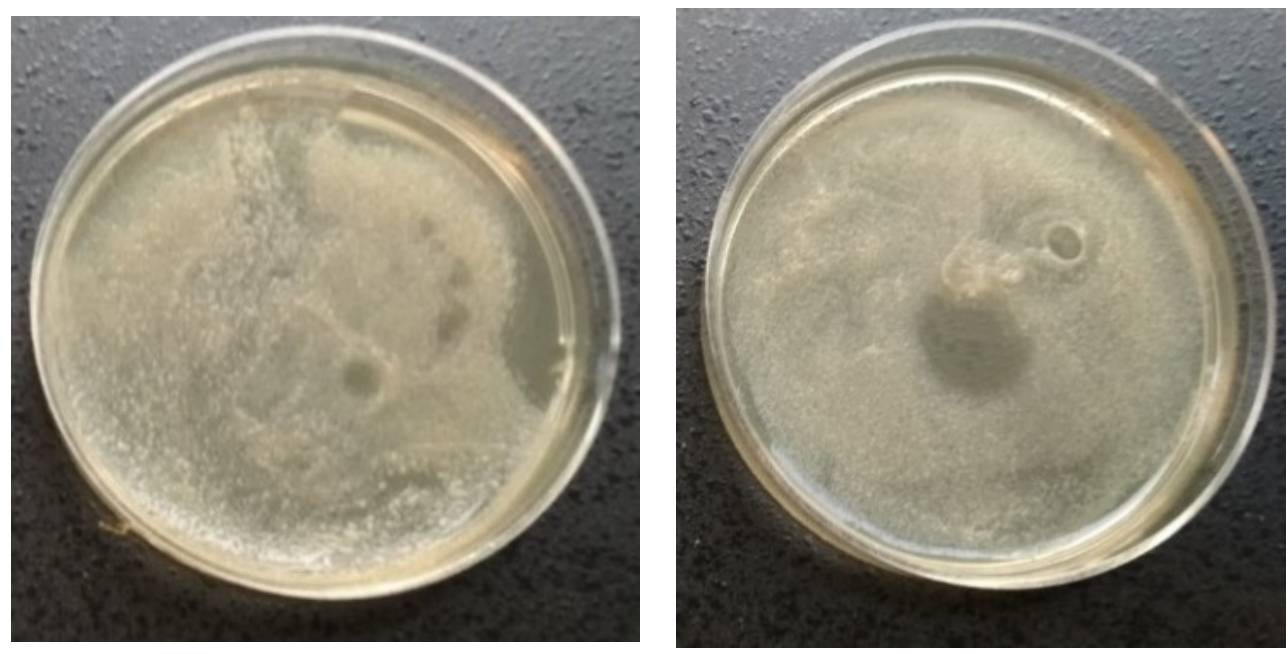

Figure 2. Comparison of inhibition zone sizes created by $10 \mathrm{~s} \mathrm{(left)} \mathrm{and} 120 \mathrm{~s}$ (right) plasma treatment with $9 \mathrm{~W}$ power after $48 \mathrm{~h}$ from the exposure of the undiluted culture.

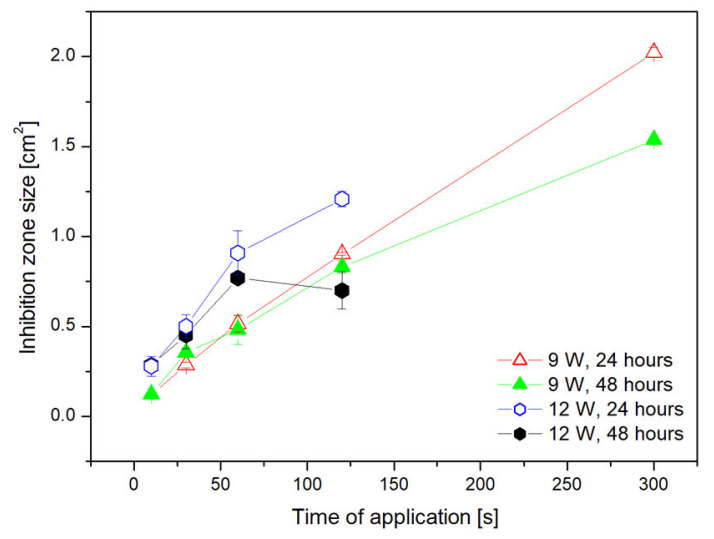

Figure 3. The dependence of the inhibition zone size on the plasma exposure time for the original undiluted culture.

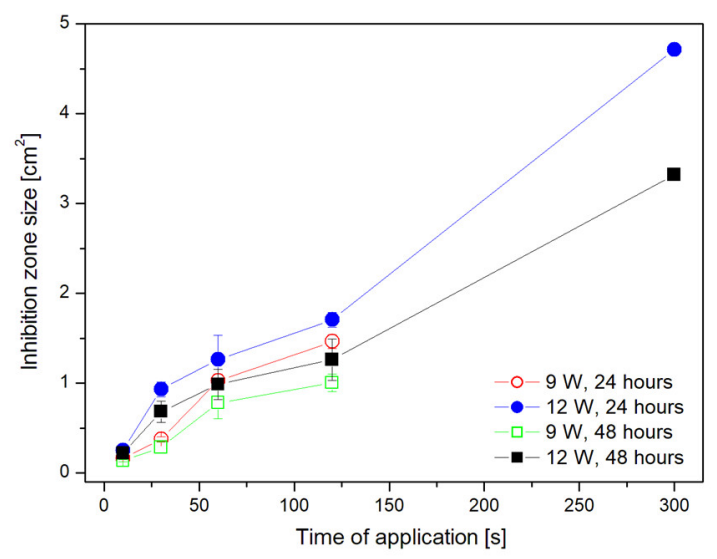

Figure 4. The dependence of the inhibition zone size on the plasma exposure time for the 10-fold dilution. 


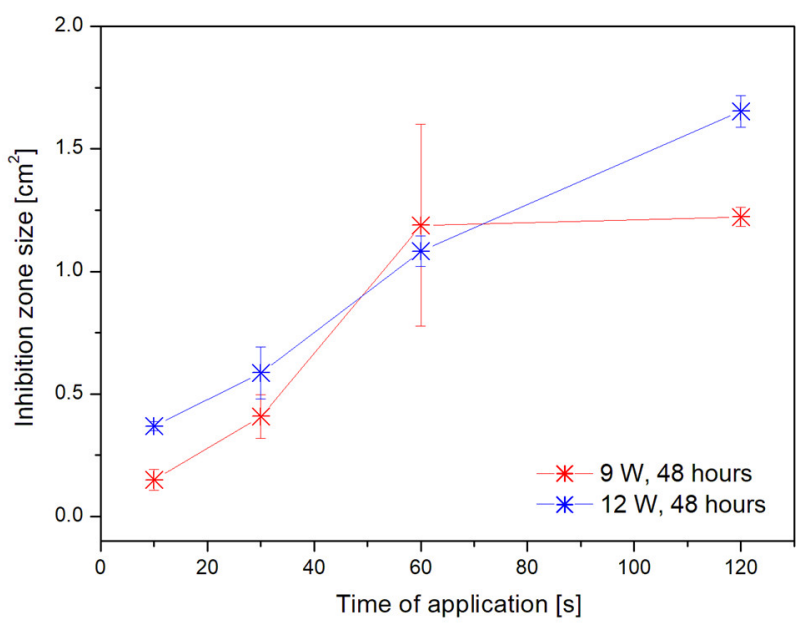

Figure 5. The dependence of the inhibition zone size on the plasma exposure time for the 100-fold dilution. Data after $24 \mathrm{~h}$ are missing because the inhibition zone was not clear enough at this stage.

\subsection{Applied Power Impact}

A similar trend to in the case of the exposure time is also valid for the impact of the power used for the treatment. The results shown in Figures 3-5 demonstrate that the power of $12 \mathrm{~W}$ is more effective than $9 \mathrm{~W}$, since by applying the greater power, bigger inhibition zones were created at all concentrations. The statistical analysis of the obtained inhibition zone sizes is presented in Table 1 . All data are based on the mean \pm standard deviation $(n=6)$ and different letter(s) A-F represent points that are statistically different $(p<0.05)$.

Table 1. Statistical analysis of results evaluating inhibition zone sizes; points with different letter(s) A-F are statistically different $(p<0.05)$ according to the mean \pm SD $(n=6)$.

\begin{tabular}{|c|c|c|c|c|c|c|c|c|c|c|}
\hline \multirow{3}{*}{$\begin{array}{c}\begin{array}{c}\text { Time of } \\
\text { Application [s] }\end{array} \\
\text { Power } \\
\text { Incubation }\end{array}$} & \multicolumn{4}{|c|}{ Undiluted Culture } & \multicolumn{4}{|c|}{ 10-Fold Diluted Culture } & \multicolumn{2}{|c|}{$\begin{array}{c}\text { 100-Fold } \\
\text { Diluted Culture }\end{array}$} \\
\hline & \multicolumn{2}{|c|}{$9 \mathrm{~W}$} & \multicolumn{2}{|c|}{$12 \mathrm{~W}$} & \multicolumn{2}{|c|}{$9 \mathrm{~W}$} & \multicolumn{2}{|c|}{$12 \mathrm{~W}$} & $9 \mathrm{~W}$ & $12 \mathrm{~W}$ \\
\hline & $24 \mathrm{~h}$ & $48 \mathrm{~h}$ & $24 \mathrm{~h}$ & $48 \mathrm{~h}$ & $24 \mathrm{~h}$ & $48 \mathrm{~h}$ & $24 \mathrm{~h}$ & $48 \mathrm{~h}$ & $48 \mathrm{~h}$ & $48 \mathrm{~h}$ \\
\hline 15 & A & A & B & B & A & A & A, B & A, B & A & B \\
\hline 30 & B & B & $\mathrm{C}$ & C & B & B & C, D & $\mathrm{C}$ & B & $\mathrm{B}, \mathrm{C}$ \\
\hline 60 & $\mathrm{C}$ & $\mathrm{B}, \mathrm{C}$ & $\mathrm{D}, \mathrm{E}$ & $\mathrm{D}$ & C, D & $\mathrm{C}$ & $\mathrm{D}$ & C, D & C, D & $\mathrm{C}$ \\
\hline 120 & $\mathrm{D}$ & $\mathrm{D}$ & $\mathrm{E}$ & C, D & $\mathrm{D}$ & C, D & $\mathrm{D}, \mathrm{E}$ & C, D & $\mathrm{C}$ & $\mathrm{D}$ \\
\hline 300 & G & $\mathrm{F}$ & - & - & - & - & $\mathrm{F}$ & $\mathrm{E}$ & - & - \\
\hline
\end{tabular}

Inhibition zones created using $12 \mathrm{~W}$ were twice as big as the ones created by $9 \mathrm{~W}$, so we can state that the power of $12 \mathrm{~W}$ has double the impact on the inhibition of Candida glabrata compared to $9 \mathrm{~W}$. From the measured inhibition zone sizes, one may conclude that for the creation of an inhibition zone of the same size, it is possible to use $12 \mathrm{~W}$ and reduce the exposure time to half compared to $9 \mathrm{~W}$ (Figure 6). For example (see Figure 4), to create the zone with the size of $1 \mathrm{~cm}^{2}$, in the case of the 10-fold dilution, the power of $9 \mathrm{~W}$ had to be applied for $1 \mathrm{~min}$, but by using the power of $12 \mathrm{~W}$, the exposure time was reduced to $30 \mathrm{~s}$. Another example might be the original concentration and the zone of $0.75 \mathrm{~cm}^{2}$ (see Figure 3). For the creation of this zone, the exposure time had to be $2 \mathrm{~min}$ when using $9 \mathrm{~W}$, but the zone of the same size was reached just after 1 min using the power of $12 \mathrm{~W}$. This trend also fits to all concentrations. 

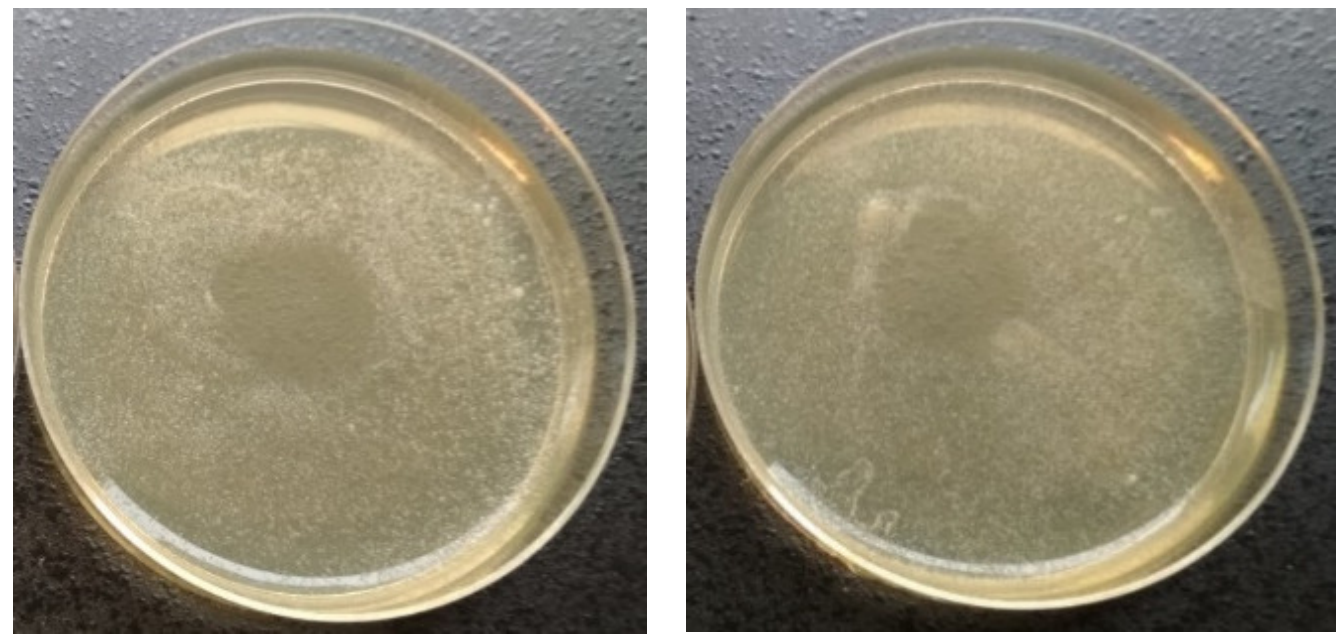

Figure 6. Comparison of exposure times needed for the creation of the same zone size when using $120 \mathrm{~s}$ at $9 \mathrm{~W}$ (left) or $60 \mathrm{~s}$ at $12 \mathrm{~W}$ (right) in the case of the 10 -fold dilution after the $24 \mathrm{~h}$ cultivation.

It can also be noticed that the sizes of the inhibition zones decreased after $48 \mathrm{~h}$, which was due to the recolonization of the zones (Figure 7). After the application of $9 \mathrm{~W}$, a greater reduction in the inhibition zones was observed than in the case of the power of $12 \mathrm{~W}$ (see Figure 8). Thus, another advantage of using $12 \mathrm{~W}$ is a longer stability of the inhibition zones. The overgrowth of the inhibition zones was due to the colonization of surrounding cells or incomplete inhibition of yeast cells at the edges of the zones. The regrowth was observed mainly in the peripheral regions of the inhibition zones, and therefore, we conclude that the interior of the zone was sufficiently inhibited, thanks to which the re-occurrence of the colonies inside the inhibition zones was very rarely observed.

Paradoxically, the largest inhibition zones had overgrown more intensively after $48 \mathrm{~h}$ than the smaller zones. An exception was the power of $12 \mathrm{~W}$ applied for $5 \mathrm{~min}$ to the 10 -fold dilution, where the largest inhibition zone in the experiment was measured (see Figure 9). However, our aim was to keep the treatment time and power as short and low as possible; therefore, we did not perform further experiments for longer times under different conditions.
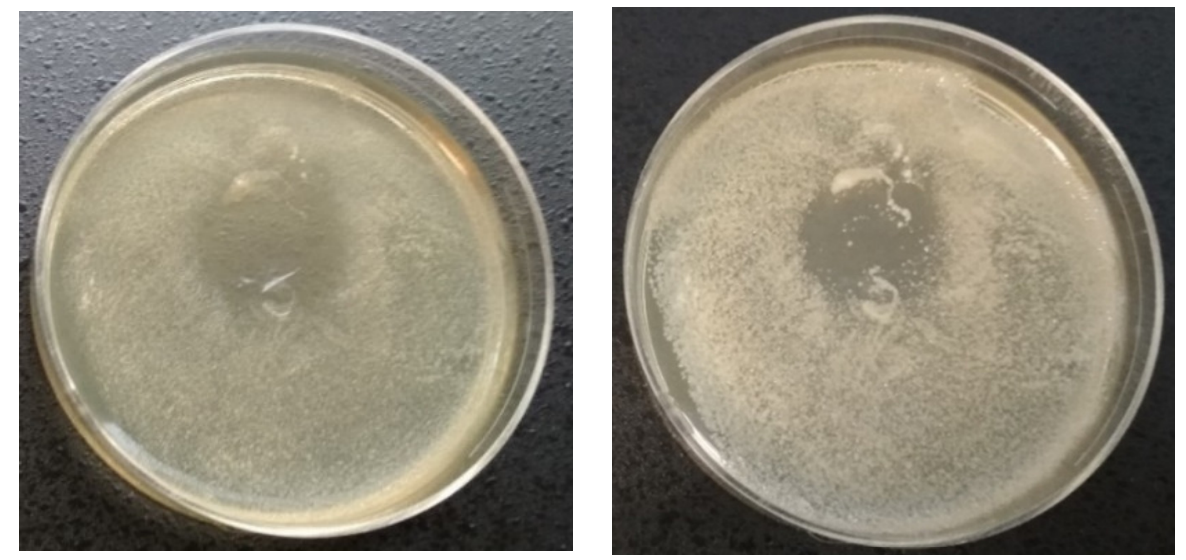

Figure 7. Inhibition zone observed after $24 \mathrm{~h}$ from the $5 \mathrm{~min}$ treatment of the undiluted culture using $9 \mathrm{~W}$ power (left)and the regrowth of the peripheral regions of the zone after the $48 \mathrm{~h}$ cultivation (right). 

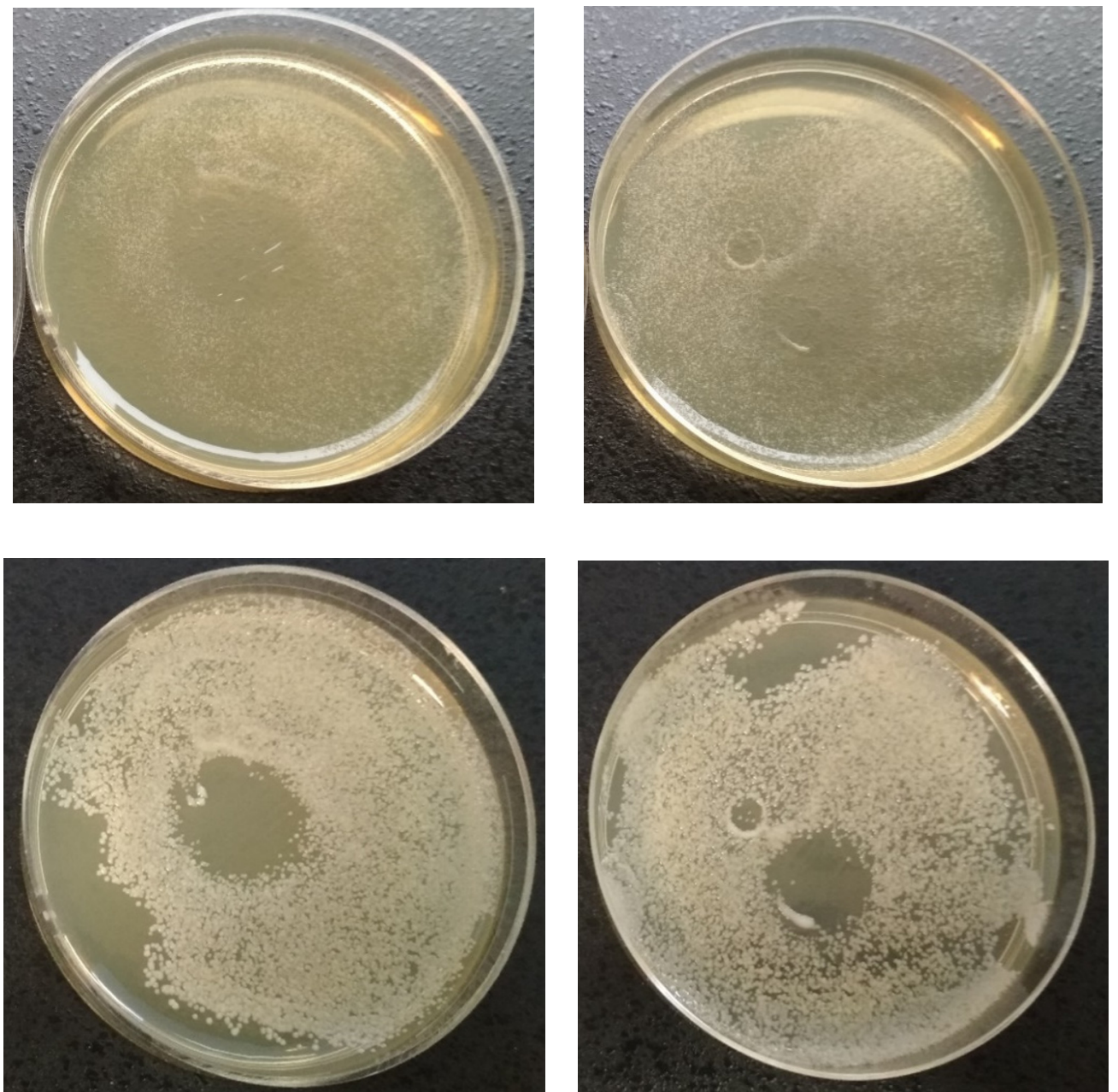

Figure 8. Comparison of the regrowth after the $24 \mathrm{~h}$ (top) and $48 \mathrm{~h}$ (bottom) cultivation of the 10-fold dilution after the 2 min treatment with the use of $9 \mathrm{~W}$ (right) or $12 \mathrm{~W}$ (left) power.

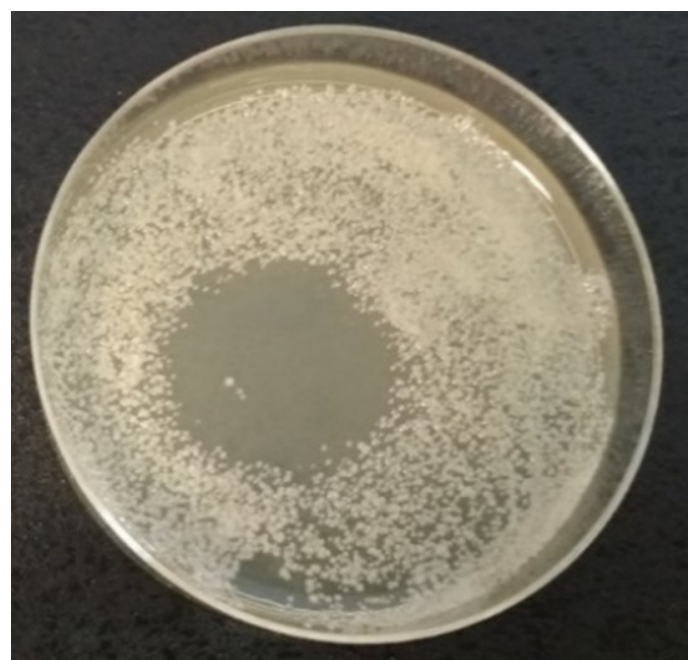

Figure 9. Picture of the largest zone created in the experiment using $12 \mathrm{~W}$ power for $5 \mathrm{~min}$ in the case of the 10-fold dilution. 


\subsection{Initial Cell Concentration Impact}

The influence of the initial cell concentration of Candida glabrata on the microwave discharge inhibition efficiency was observed using undiluted culture, 10- and 100-fold dilutions of Candida glabrata. In general, we can say that the size of the inhibition zones increased with the lower cell concentration, namely that the largest zones could be observed for the 100-fold dilution, even after the shorter plasma exposure time (see Figures 10 and 11).

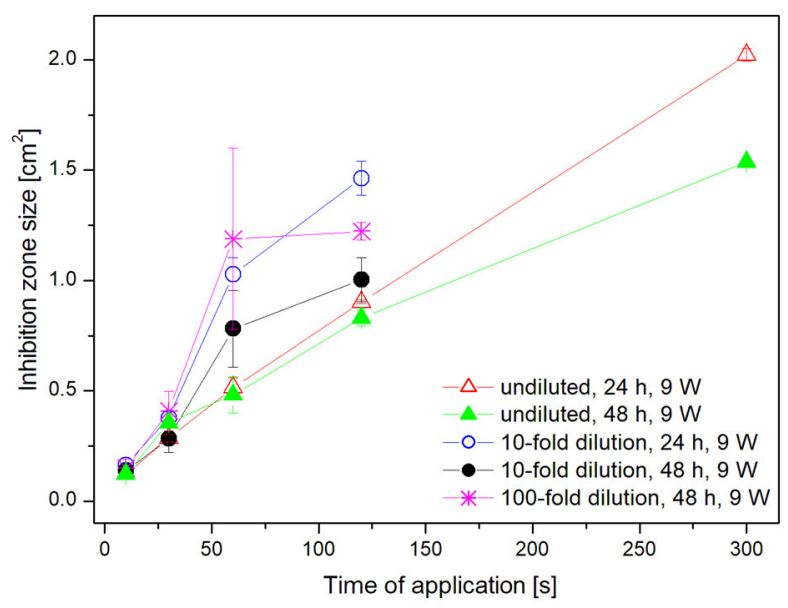

Figure 10. Dependence of the inhibition zone size on the exposure time using power of $9 \mathrm{~W}$.

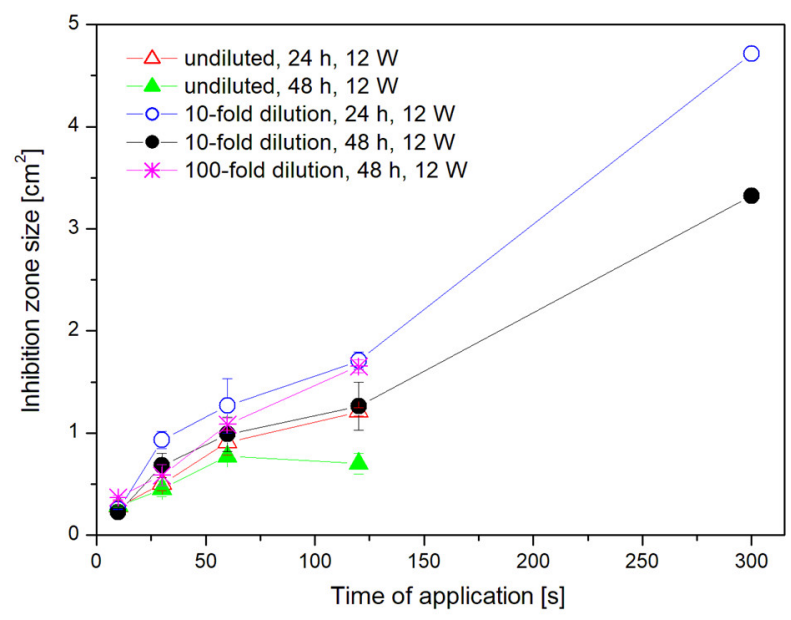

Figure 11. Dependence of the inhibition zone size on the exposure time using power of $12 \mathrm{~W}$.

However, for the 100-fold dilution, a homogeneous distribution of the cells over the entire surface of the Petri dish cannot be guaranteed, and therefore the parallel measurements differed more than the in case of the original concentration or the 10-fold dilution. Additionally, it was impossible to calculate the inhibition zone at the 100 -fold dilution due to the low yeast concentration after the $24 \mathrm{~h}$ incubation.

Based on our previous experimental results obtained by optical emission spectroscopy [34], we suppose the action of reactive oxygen and nitrogen species (RONS) produced by our torch that can play a significant role in the decontamination process. Even though we used pure argon as the carrier gas, molecules contained in the surrounding air (oxygen, nitrogen, water vapor, etc.) were swept into the plasma flow where they were excited or ionized. Therefore, the presence of RONS such as nitrogen monoxide radical $(\mathrm{NO})$, hydroxyl radical $(\mathrm{OH})$, atomic oxygen $(\mathrm{O})$, peroxynitrite molecule $(\mathrm{ONOOH})$ or ozone $\left(\mathrm{O}_{3}\right)$ was determined in our plasma torch [34]. The NO radical is very reactive and, in a reaction with water, forms nitrous acid, which decreases the substrate $\mathrm{pH}$. This effect might contribute to the deactivation of some kinds of microorganisms. In addition, the $\mathrm{OH}$ radical is well 
known as one of the strongest nonselective oxidative species. Furthermore, UV radiation of the NO radical belongs to the UVC region, which is well known for its bactericide effects [14].

\section{Conclusions}

The target of this work was to study the effects of the microwave low-temperature plasma torch on the yeast Candida glabrata. The $24 \mathrm{~h}$ inoculum was spread on the top of the agar plates in the Petri dishes and then exposed to the microwave discharge. The evaluation of inhibitory effects was based on the size of the inhibition zones formed during the subsequent cultivation and their time stability at 24 and $48 \mathrm{~h}$ after the treatment. The results showed that even after a short time exposition (10 s), it is possible to observe the formation of inhibition zones, the size of which increases with the increasing treatment time. It is similar in the case of the applied power effect; higher power leads to the formation of bigger inhibition zones. The effect is not linear because the change of power from 9 to $12 \mathrm{~W}$ leads to the same inhibition area formation in half the time. By monitoring the effect of concentration, it was found that with a smaller number of cells, and thus their lower cohesion, larger and more stable inhibition zones occur. When trying to expose the already formed biofilm, the inhibition zone formation was not observable, mainly due to the multilayer structure of the biofilm and its high compactness [9].

It is clear from the experiments that a power of $12 \mathrm{~W}$ is more effective, and the inhibitory effects are much higher. However, the disadvantage of its use may be the higher temperature generated, especially during the prolonged treatment. From the viewpoint of the usage, it would therefore depend on the origin of the exposed object. From the knowledge of the yeast Candida glabrata, we know that it is a threat, especially in hospitalized patients. Thus, in the case of the sterilization of medical instruments or other inanimate objects, the higher temperature should not be a problem and the power of $12 \mathrm{~W}$ (or even more) could be advantageously used to speed up and improve the sterilization. However, if the exposed objects are alive, such as human tissues affected by candidiasis, it would certainly be more sensible to choose a shorter exposition time ( $9 \mathrm{~W}$ power) and repeat the process several times to avoid any damage on the healthy tissues. When working at $12 \mathrm{~W}$ for a longer time, the top of the temperature range could easily be reached, and the treatment may not be comfortable for the patient. However, these hypotheses are not proven by working on the living tissue, and therefore further experiments would be needed to confirm them. Another perspective for future experiments is to determine the vitality or inhibition of yeast cells using selective dyes and the separate monitoring of individual active plasma particles, their effects, radiation and heat produced to analyze their effect on the inhibition. Preliminary experiments using different dyes immobilized in the agar plates have already shown a correlation between the size of the inhibition zone and the active particles distribution on the treated surface. This detailed study is currently proceeding. After an independent monitoring, it would be possible to evaluate the synergistic effect of individual factors and plasma particles on the yeasts.

Author Contributions: Conceptualization F.K. and P.M.; methodology K.T., F.K., and P.M.; investigation K.T., F.K., Z.K., and P.M.; writing - original draft preparation K.T., F.K., and P.M. review and editing K.T., F.K., Z.K., and P.M. All authors have read and agreed to the published version of the manuscript.

Funding: This research received external funding from EU cohesion funds, program INTEREG SK-CZ, project No. 304011P709.

Conflicts of Interest: The authors declare no conflict of interest.

\section{References}

1. Grzegorzewski, F. Influence of Non-Thermal Plasma Species on the Structure and Functionality of Isolated and Plantbased 1,4-Benzopyrone Derivatives and Phenolic Acids. Ph.D. Thesis, Technische Universität Berlin, Berlin, German, 2011.

2. Soloshenko, I.A.; Tsiolko, V.V.; Pogulay, S.S.; Kalyuzhnaya, A.G.; Bazhenov, V.Y.; Shchedrin, A.I. Effect of Water Adding on Kinetics Of Barrier Discharge in Air. Plasma Sources Sci. Technol. 2009, 18, 045019. [CrossRef] 
3. Dobrynin, D.; Fridman, G.; Fridman, G.; Dridman, A. Physical and Biological Mechanisms of Direct Plasma Interaction with Living Tissue. N. J. Phys. 2009, 11, 115020. [CrossRef]

4. Misra, N.; Tiwari, B.K.; Raghavarao, K.S.M.S.; Cullen, P.J. Nonthermal Plasma Inactivation of Food-Borne Pathogens. Food Eng. Rev. 2011, 3, 159-170. [CrossRef]

5. Fröhling, A.; Durek, J.; Schnabel, U.; Ehlbeck, J.; Bolling, J.; Schlüter, O. Indirect Plasma Treatment of Fresh Pork: Decontamination Efficiency and Effects on Quality Attributes. Innov. Food Sci. Emerg. Technol. 2012, 16, 381-390. [CrossRef]

6. Hertwig, C.; Reineke, K.; Ehlbeck, J.; Erdoğdu, B.; Rauh, C.; Schlüter, O. Impact of Remote Plasma Treatment on Natural Microbial Load and Quality Parameters of Selected Herbs and Spices. J. Food Eng. 2015, 167, 12-17. [CrossRef]

7. Ehlbeck, J.; Schnabel, U.; Andrasch, M.; Stachowiak, J.; Stolz, N.; Fröhling, A.; Schlüter, O.; Weltmann, K.-D. Plasma Treatment of Food. Contrib. Plasma Phys. 2015, 55, 753-757. [CrossRef]

8. Moritz, M.; Wiacek, C.; Koethe, M.; Braun, P.G. Atmospheric Pressure Plasma Jet Treatment of Salmonella Enteritidis Inoculated Eggshells. Int. J. Food Microbiol. 2017, 245, 22-28. [CrossRef]

9. Won, M.Y.; Lee, S.J.; Min, S.C. Mandarin Preservation by Microwave-Powered Cold Plasma Treatment. Innov. Food Sci. Emerg. Technol. 2017, 39, 25-32. [CrossRef]

10. Lukeš, P.; Locke, B.R.; Brisset, J.L. Aqueous-phase chemistry of electrical discharge plasma in water and in gas-liquid environments. In Plasma Chemistry and Catalysis in Gases and Liquids; Parvulescu, V.I., Magureanu, M., Lukeš, P., Eds.; Wiley: Weinheim, Germany, 2012; pp. 243-308.

11. Ono, R.; Oda, T. Ozone Production Process in Pulsed Positive Dielectric Barrier Discharge. J. Phys. D Appl. Phys. 2007, 40, 176-184. [CrossRef]

12. Koutchma, T. UV Light for Processing Foods. Ozone Sci. Eng. 2008, 30, 93-98. [CrossRef]

13. Choudhary, R.; Bandla, S. Ultraviolet Pasteurization for Food Industry. Int. J. Food Sci. Nutr. Eng. 2012, 2, 12-15. [CrossRef]

14. Sosnin, E.A.; Stoffels, E.; Erofeev, M.V.; Kieft, I.E.; Kunts, S.E. The Effects of UV Irradiation and Gas Plasma Treatment on Living Mammalian Cells and Bacteria: A Comparative Approach. IEEE Trans. Plasma Sci. 2004, 32, 1544-1550. [CrossRef]

15. Lu, P.; Cullen, P.J.; Ostrikov, K. Chapter 4-Atmospheric pressure nonthermal plasma sources. In Cold Plasma in Food and Agriculture: Fundamentals and Applications; Misra, N.N., Schluter, O., Cullen, P.J., Eds.; Elsevier Inc.: Amsterdam, The Netherlands, 2016; pp. 83-116.

16. Lee, T.; Puligundla, P.; Mok, C. Corona Discharge Plasma Jet Inactivates Food-Borne Pathogens Adsorbed Onto Packaging Material Surfaces. Packag. Technol. Sci. 2017, 30, 681-690. [CrossRef]

17. Jayasena, D.; Kim, H.J.; Cheorun, J. Dielectric barrier discharge: Meat treatment. In Encyclopedia of Plasma Technology, 1st ed.; Shohet, J.L., Ed.; CRC Press: Boca Raton, FL, USA, 2017.

18. Zhang, B.; Chen, L.; Lin, L.X.; Zhang, H. Understanding the Multi-Scale Structure and Functional Properties of Starch Modulated by Glow-Plasma: A Structure-Functionality Relationship. Food Hydrocoll. 2015, 50, 228-236. [CrossRef]

19. Stoffels, E.; Flikweert, A.J.; Stoffels, W.W.; Kroesen, G.M.W. Plasma Needle: A Non-Destructive Atmospheric Plasma Source for Fine Surface Treatment of (Bio)Materials. Plasma Sources Sci. Technol. 2002, 11, 383-388. [CrossRef]

20. Wang, Y.; Wang, T.; Yuan, Y.; Fan, Y.; Guo, K.; Yue, T. Inactivation of Yeast in Apple Juice Using Gas-Phase Surface Discharge Plasma Treatment with a Spray Reactor. LWT 2018, 97, 530-536. [CrossRef]

21. Marinova, P.; Benova, E.; Todorova, Y.; Topalova, Y.; Yotinov, I.; Atanasova, M.; Krcma, F. Surface-WaveSustained Plasma Torch for Water Treatment. J. Phys. Conf. Ser. 2018, 982, 530-536. [CrossRef]

22. Stulic, V.; Vukusic, T.; Butorac, A.; Popovic, D.; Herceg, Z. Proteomic Analysis of Saccharomyces Cerevisiae Response to Plasmatreatment. Int. J. Food Microbiol. 2019, 292, 171-183. [CrossRef]

23. Čtvrtečková, L.; Píchová, A.; Scholtz, V.; Khun, J.; Julák, J. Non-Thermal Plasma-Induced Apoptosis in Yeast Saccharomyces Cerevisiae. Contrib. Plasma Phys. 2019, 59, e201800064. [CrossRef]

24. Polčič, P.; Pakosová, L.; Chovančíková, P.; Machala, Z. Reactive Cold Plasma Particles Generate Oxidative Stress in Yeast but do not Trigger Apoptosis. Can. J. Microbiol. 2018, 64, 367-375. [CrossRef]

25. Wang, Y.; Wang, Z.R.; Zhu, X.; Yuan, Y.H.; Gao, Z.P.; Yue, T.L. Application of Electrical Discharge Plasma on the Inactivation of Zygosaccharomyces rouxii in Apple Juice. LWT-Food Sci. Technol. 2020, 121, 108974. [CrossRef] 
26. Tarabová, B.; Žilková, A.; Machala, Z. Cold Air Plasma Pasteurisation OF Fresch Apple Juice. In Proceedings of the HAKONE XV, Brno, Czech Republic, 11-16 September 2016; pp. 453-456.

27. Starek, A.; Pawlat, J.; Chudzik, B.; Kwiatkowski, M.; Terebun, P.; Sagan, A.; Andrejko, D. Evaluation of Selected Microbial And Physicochemical Parameters of Fresh Tomato Juice after Cold Atmospheric Pressure Plasma Treatment during Refrigerated Storage. Sci. Rep. 2019, 9, 8407. [CrossRef] [PubMed]

28. Xu, H.B.; Zhu, Y.P.; Cui, D.J.; Du, M.R.; Wang, J.Q.; Ma, R.N.; Jiao, Z. Evaluating the Roles of OH Radicals, $\mathrm{H}_{2} \mathrm{O}_{2}$, ORP and $\mathrm{pH}$ in the Inactivation of Yeast Cells on a Tissue Model By Surface Micro-Discharge Plasma. J. Phys. D Appl. Phys. 2019, 52, 395201. [CrossRef]

29. Du, M.R.; Xu, H.B.; Zhu, Y.P.; Ma, R.N.; Jiao, Z. A Comparative Study of the Major Antimicrobial Agents against the Yeast Cells on the Tissue Model by Helium and Air Surface Micro-Discharge Plasma. AIP Adv. 2020, 10, 025036. [CrossRef]

30. Benova, E.; Atanasova, M.; Bogdanov, T.; Marinova, P.; Krčma, F.; Mazánková, V.; Dostál, L. Microwave Plasma Torch at a Water Surface. Plasma Med. 2016, 6, 59-65. [CrossRef]

31. Benova, E.; Marinova, P.; Atanasova, M.; Petrova, T. Surface-Wave-Sustained Argon Plasma Kinetics from Intermediate to Atmospheric Pressure. J. Phys. D Appl. Phys. 2018, 51, 474004. [CrossRef]

32. Bogdanov, T.; Benova, E. Theoretical Parametric Investigation of Plasma Sustained by Traveling Electromagnetic Wave in Coaxial Configuration. Vacuum 2018, 155, 280-291. [CrossRef]

33. Krčma, F.; Tsonev, I.; Smejkalová, K.; Truchlá, D.; Kozáková, Z.; Zhekova, M.; Marinova, P.; Bogdanov, T.; Benova, E. Microwave Micro Torch Generated in Argon Based Mixtures for Biomedical Applications. J. Phys. D Appl. Phys. 2018, 51, 414001. [CrossRef]

34. Bogdanov, T.; Tsonev, I.; Marinova, P.; Benova, E.; Rusanov, K.; Rusanova, M.; Atanassov, I.; Kozáková, Z.; Krčma, F. Microwave Plasma Torch Generated in Argon for Small Berries Surface Treatment. Appl. Sci. 2018, 8, 1870. [CrossRef]

35. Narimisa, M.; Krčma, F.; Onyshchenko, Y.; Kozáková, Z.; Morent, R.; De Geyter, N. Atmospheric Pressure Microwave Plasma Jet for Organic Thin Film Deposition. Polymers 2020, 12, 354. [CrossRef]

36. Lebedev, Y.A. Microwave Discharges at Low Pressures and Peculiarities of the Processes in Strongly Non-Uniform Plasma. Plasma Sources Sci. Technol. 2015, 24, 53001. [CrossRef]

37. Fidel, P.L.; Vazquez, J.A.; Sobel, J.D. Candida glabrata: Review of Epidemiology, Pathogenesis, and Clinical Disease with Comparison to C. albicans. Clin. Microbiol. Rev. 1999, 12, 80-96. [CrossRef] [PubMed]

38. Ahmad, K.M.; Kokošar, J.; Guo, X.; Gu, Z.; Ishchuk, O.P.; Piškur, J. Genome Structure and Dynamics of the Yeast Pathogen Candida Glabrata. Fems Yeast Res. 2014, 14, 529-535. [CrossRef] [PubMed]

39. Mendes-Giannini, M.J.S.; Bernardi, T.; Scorzoni, L.; Fusco-Almeida, A.M.; Sardi, J.C.O. Candida Species: Current Epidemiology, Pathogenicity, Biofilm Formation, Natural Antifungal Products and New Therapeutic Options. J. Med. Microbiol. 2013, 62, 10-24.

40. Sykes, J.E. Candidiasis. Canine Feline Infect. Dis. 2014, 67, 653-659.

41. Rodrigues, C.; Rodriguez, M.; Silva, S.; Henriques, M.; Ishchuk, O.P.; Piškur, J. Candida glabrata Biofilms: How Far Have we Come? J. Fungi 2017, 3, 11. [CrossRef]

42. Czech Microorganism Collection. Available online: https://www.sci.muni.cz/ccm/index.html (accessed on 6 August 2020).

(C) 2020 by the authors. Licensee MDPI, Basel, Switzerland. This article is an open access article distributed under the terms and conditions of the Creative Commons Attribution (CC BY) license (http://creativecommons.org/licenses/by/4.0/). 